\title{
POLÍTICAS DE FORMAÇÃO E GESTÃO PEDAGÓGICA: O DESAFIO DA SIMETRIA INVERTIDA
}

http://dx.doi.org/10.5902/2318133821142

\author{
Marciele Taschetto da Silva \\ Universidade Federal de Santa Maria, Brasil.
}

\author{
Adriana Moreira da Rocha \\ Universidade Federal de Santa Maria, Brasil.
}

\begin{abstract}
Resumo
Este estudo encontra-se inserido no contexto investigativo sobre formação de formadores e a gestão pedagógica da área de Ciências Exatas e da Terra. Ressaltamos que a gestão pedagógica se constitui a medida que o professor se compromete com seu projeto de ensino, organizando e articulando saberes necessários para a formação de seus alunos e, consequentemente, para a sua própria formação. Desse modo, este trabalho trata-se de um estudo bibliográfico, tendo como objetivo analisar definições teóricas e conceituais relevantes para repensar a gestão pedagógica na formação docente inicial e o reflexo desta na educação básica, em busca da qualidade do ensino na área de Ciências Exatas e da Terra. Em relação a esta temática sabemos que os docentes universitários possuem a responsabilidade e compromisso social com a ampla formação de futuros profissionais para além da mera transmissão de conhecimentos. Assim preocupa-nos refletir sobre a relação existente entre a gestão da aula dos docentes atuantes nos cursos de licenciatura e a formação ofertada aos futuros professores da educação básica. Esta relação apresenta certa dubiedade, pois ao mesmo tempo em que os professores realizam a gestão de suas aulas a fim de oferecerem uma boa formação para seus alunos, não são formados nem preparados para tal exercício. Desse modo, a gestão de sua aula é regida por saberes constituídos no seu cotidiano, decorrentes de esforços individuais, sob o prisma da pedagogia universitária.
\end{abstract}

Palavras-chave: gestão pedagógica, formação de formadores, formação inicial.

\section{TRAINING POLICY AND EDUCATIONAL MANAGEMENT UNIVERSITY: THE CHALLENGE OF SYMMETRY MIRROR}

\begin{abstract}
This is an investigative research in the area of teacher education and educational management in the field of Exact and Earth Sciences. It is emphasized that educational management is composed at the same time as the teachers are compromised with their teaching project, organizes and articulating the necessary knowledge for the student's formation and, consequently, for their own development. Thus, this study is a bibliographical research, aiming to examine relevant theoretical and conceptual definitions in order to think educational management in initial teacher training, and
\end{abstract}


its reflection within basic education, in pursuit of an education of quality in the field of Exact and Earth Sciences. In relation to this issue, it is known that college professors have the responsibility and social commitment to extensive training of future professionals that goes beyond the mere transmission of knowledge. Thus, it is a concern to reflect on the relationship between class management of professors in undergraduate courses and the training offered to prospective teachers of basic education. This relationship presents some ambiguity, due to the fact that at the same time that teachers perform the management of their classes in order to provide a good education for their students, they are not trained and prepared for such. Therefore, the management of their classes is governed by knowledge conventionalized in their daily life, arising from individual efforts, under the perspective of university pedagogy.

Key-words: educational management, teacher education, initial education. 


\section{Considerações iniciais}

- ste estudo trata-se de um recorte de uma monografia defendida no Curso de - Especialização em Gestão Educacional, inserida no contexto investigativo sobre formação de formadores e a gestão pedagógica da área de Ciências Exatas e da Terra.

A justificativa deste trabalho se dá pelo fato de que os docentes dos cursos de licenciatura possuem o compromisso com a formação de professores que atuam ou atuarão no ensino básico. Contudo, diversos estudos evidenciam a falta de proximidade entre o contexto universitário e o escolar. Fato este possivelmente decorrente das próprias políticas de formação de professores que acabam influenciando na postura ainda assumida pelos docentes universitários, em que seguem o modelo de aula ultrapassado com a centralidade na transmissão de seus conhecimentos específicos. A gestão da aula universitária compreende as dinâmicas desenvolvidas pelos professores no espaço-tempo da sala de aula em consonância com o projeto pedagógico institucional em prol da criação de um ambiente favorável para o desenvolvimento do ensino e aprendizagem efetiva (Ferreira, 2008).

Desse modo, percebemos que a formação exigida pelos professores universitários, na forma de lei, é direcionada para os cursos de mestrado e doutorado, sendo que estes não formam para o ensino, mas possuem o foco na formação do pesquisador. Este trabalho tem como proposta refletir sobre a gestão da aula universitária, como atividade que caracteriza a identidade profissional docente e está diretamente ligada a formação dos professores do ensino básico. Assim, apresentamos como objetivo analisar definições teóricas e conceituais relevantes para repensarmos a gestão pedagógica na formação docente inicial e o reflexo desta na educação básica, em busca da excelência do ensino na área de Ciências Exatas e da Terra.

O presente trabalho se trata de uma contribuição teórica, em que buscamos apresentar modelos e conceitos ancorados sobre o tema gestão pedagógica da aula, considerando a repercussão das políticas de formação e a gestão da aula universitária na formação inicial dos professores da educação básica.

\section{Gestão pedagógica da aula universitária}

A gestão, compreendida como tomada de decisão, organização, direção e participação (Lück, 2009) ocorre em todos os âmbitos das instituições educacionais. De acordo com Ferreira $(2008$, p. 8) a gestão se desenvolve "fundamentalmente na sala de aula, onde concretamente se objetiva o Projeto Politico Pedagógico não só como desenvolvimento do planejado, mas como fonte privilegiada de novos subsídios para novas tomadas de decisões". Para Libâneo (2004) a gestão, que está diretamente relacionada com os princípios de democratização e participação, implica na busca de objetivos comuns pela coordenação, o colegiado e demais profissionais da educação, onde cada um assume sua parte na execução de suas práticas para alcançarem um objetivo geral coletivo.

Apesar dos autores referirem-se à gestão pedagógica ligada à educação básica, no ensino superior as atribuições docentes não são diferentes. Todo curso de graduação possui seu projeto político pedagógico de curso, onde são explicitados os objetivos do curso, o papel que o professor deve assumir, bem como o perfil do aluno que se pretende 
formar relacionando com as áreas de atuação. Desse modo, cabe ao professor desenvolver o seu trabalho de acordo com o projeto defendido e almejado pelo curso. Nesta direção,

A gestão pedagógica, também, está ancorada nos saberes da docência que podem ser traduzidos pelo conhecimento aprofundado de um dado campo de estudos; pela produção e manejo de materiais didáticos; pelo domínio de instrumentos metodológicos; pela clareza quanto à opção epistemológica e quanto ao nível cognitivo e intelectual esperado dos alunos durante as situações de aprendizagem; pela criatividade e bom senso na elaboração de situações que desafiem o pensamento e que produzam a novidade; pela capacidade de organizar o planejamento das aulas, as atividades de aprendizagem e a avaliação dos alunos; e pelo espírito investigativo que permite a elaboração própria, o pensamento autônomo e a autoavaliação. (Lunardi, 2012, p. 96)

A gestão pedagógica se constrói à medida que o professor se compromete com seu projeto de ensino, organizando e articulando saberes necessários para a formação de seus alunos e, consequentemente, para a sua própria formação. Desse modo, compreendemos que

o conhecimento do professor é composto da sensibilidade da experiência e da indagação teórica. Emerge da prática (refletida) e se legitima em projetos de experimentação reflexiva e democrática no próprio processo de construção e reconstrução das práticas institucionais. (Pimenta; Anastasiou, 2002, p. 185)

Assim, compreendemos a gestão pedagógica como o processo que envolve todos os âmbitos da docência, desde os saberes didáticos, visão social e compreensão das possibilidades e limitações de cada contexto, conhecimentos específicos da área, conhecimentos experienciais da profissão, produção dos conhecimentos, até a capacidade do professor de fazer a articulação de todos esses conhecimentos, direcionando-os ao ensino, que é o que caracteriza e dá sentido à profissão professor.

Oliveira (2013) ressalta que "o ensinar não é transferir conhecimento, pois demanda ao professor ter uma postura crítica, ter curiosidade, ter rigor metodológico para ensinar e fazer uma leitura de mundo, de forma crítica e ter criatividade para adequar o ensino às reais necessidades dos estudantes, respeitando os seus saberes" (p. 47).

Verificamos, agora nas palavras de Oliveira (2013), ainda que implicitamente, a importância da competência pedagógica como centro do processo da gestão da sala de aula, uma vez que ensinar requer a capacidade de atuar nos cenários educativos de forma crítico-reflexiva, não se restringindo ao domínio do conteúdo, às habilidades de ensino e aspectos administrativos, mas envolvendo um processo de reflexão permanente sobre o processo de ensino e aprendizagem, contribuindo para o próprio desenvolvimento profissional (Morosini et al., 2006).

Nesta mesma direção, compreendemos que para Bolzan e Isaia (2006) o papel do professor vai além do domínio da área de conhecimento, pois este exercício perpassa pelo menos três dimensões: o conhecimento científico, o conhecimento pedagógico compartilhado e o conhecimento profissional. 
É essencial que o docente domine os conhecimentos de sua área específica de formação, porém precisa ter consciência da importância da dimensão pedagógica para a transposição de seu conhecimento. Esta envolve formas de conceber e desenvolver o ensino, proporcionando ao professor refletir sobre a sua prática, percebendo-se como mediador do processo de aprendizagem. A dimensão pedagógica oferece suportes para que ocorra uma interlocução entre a dimensão do conhecimento específico e a dimensão do conhecimento profissional, pois integra tanto o saber e o saber-fazer de determinada profissão. É pela dimensão pedagógica que o docente cria subsídios capazes de auxiliar o estudante na elaboração de suas próprias estratégias de apropriação desses saberes, afim de que estes se tornem capazes de aplicar esse saber em diferentes situações em sua futura profissão, contribuindo deste modo para autonomia desses futuros profissionais.

Dessa forma, para que ocorra essa interlocução, é necessário que o docente apresente, além de conhecimentos relacionados às diferentes profissões para as quais está formando os seus estudantes, o domínio da dimensão pedagógica. Contudo, os estudos realizados apresentam indicadores de que a dificuldade apresentada pela maioria dos professores está relacionada ao fato de que a dimensão pedagógica não se faz presente na formação do professor de ensino superior. Este indicador aponta certa redundância, pois ao mesmo tempo em que estes docentes não foram preparados para 0 exercício de sua profissão, se espera deles a responsabilidade de preparar futuros educadores.

\section{Políticas de formação de professores}

A gestão do pedagógico do professor universitário repercute na formação inicial de futuros educadores e isso nos encaminha a refletirmos sobre o contexto das políticas de formação de professores. A gestão do pedagógico é a ação previamente planejada e realizada pelo professor, que possui autonomia de exercê-la, mas que concretiza em sua atuação as propostas construídas coletivamente nos documentos oficiais que respaldam e norteiam a sua ação como formador.

Deste modo, nos cabe discutir o histórico de mudanças nos cursos de licenciaturas, bem como na área de Ciências Exatas e da Terra e os principais documentos que norteiam as práticas docentes, apresentando propostas sobre a formação que deve ser ofertada aos professores do ensino básico: parâmetros curriculares nacionais, as diretrizes curriculares nacionais para a formação de professores, bem como as resoluções CNE/CP n.1 e n.2, 2002 e os pareceres CNE/CP 9 e 28 de 2001.

Ao discutirmos os parâmetros curriculares nacionais é importante ressaltarmos que estes foram criados na tentativa de construir referências nacionais comuns ao processo educativo em todas as regiões brasileiras, para que assim todos pudessem ter acesso a um conjunto de conhecimentos socialmente elaborados e reconhecidos como necessários ao exercício da cidadania. No que tange especificamente aos PCN's para a área de Ciências Exatas, foco deste estudo, vemos que as propostas são dirigidas aos educadores, tendo como objetivo aprofundar a prática pedagógica de Ciências Exatas e da Terra na escola fundamental, trazendo aspectos sinalizando a importância do planejamento de seu trabalho e para o projeto pedagógico da sua equipe escolar e do sistema de ensino do qual faz parte. 
De acordo com a resolução CNE/CP n. 1, de 18 de fevereiro de 2002, que institui as diretrizes curriculares para a formação de professores, no artigo $3^{\circ}$, inciso II, a formação oferecida deve corresponder à formação esperada pelo futuro profissional, havendo harmonia entre a situação de formação e atuação. Assim, estende-se a responsabilidade ao docente se adaptar e se atualizar diante a responsabilidade de ser e formar esse novo perfil de profissional. No entanto, a maioria dos professores que atuam no ensino superior, sem preparação para a docência superior, acaba reproduzindo a formação que tiveram durante sua experiência como aluno no ensino básico ou na graduação, em um tempo-espaço bastante diferente da atual realidade.

Outra problemática referente aos cursos de licenciatura, que é apresentada como uma das questões a serem enfrentadas na formação de professores pela resolução CNE/CP 2002, é a desvalorização dos cursos de licenciatura e a centralização destes nas áreas específicas de conhecimento:

No caso da formação nos cursos de licenciatura, em seus moldes tradicionais, a ênfase está contida na formação nos conteúdos da área, onde o bacharelado surge como a opção natural que possibilitaria, como apêndice, também, o diploma de licenciado. Neste sentido, nos cursos existentes, é a atuação do físico, do historiador, do biólogo, por exemplo, que ganha importância, sendo que a atuação destes como "licenciados" torna-se residual e é vista, dentro dos muros da universidade, como "inferior", em meio à complexidade dos conteúdos da "área", passando muito mais como atividade "vocacional" ou que permitiria grande dose de improviso e autoformulação do "jeito de dar aula". (Brasil, 2002, p. 16)

A desvalorização profissional resulta de diversos fatores, desde os baixos salários dos professores da educação básica, a maçante carga horária de trabalho, a falta de incentivo à formação continuada em exercício e no caso do ensino superior, o ingresso de docentes nas IES que se dá pela valorização da produção científica, a supervalorização da pesquisa sobreposta as práticas em sala de aula. Como consequência da crescente perda de prestígio da profissão, há pouca procura pelos cursos de licenciaturas por estudantes talentosos, que poderiam auxiliar na qualificação da educação em seus diferentes níveis (Scremin, 2014).

De acordo com o PCN de terceiro e quarto ciclos do ensino fundamental de Ciências Exatas,

propostas inovadoras têm trazido renovação de conteúdos e métodos, mas é preciso reconhecer que pouco alcançam a maior parte das salas de aula onde, na realidade, persistem velhas práticas. Mudar tal estado de coisas, portanto, não é algo que se possa fazer unicamente a partir de novas teorias, ainda que exija sim uma nova compreensão do sentido mesmo da educação, do processo no qual se aprende. (Brasil, 1998, p. 21)

Como o contexto deste estudo interessa tratar, sobretudo, das práticas dos professores universitários repercutidas na formação de professores do ensino básico, entendemos que devemos considerar todas as formas de conhecimento: teóricos e práticos, a evolução historicamente dos conhecimentos de determinada área, mas 
especialmente, que todas as áreas de conhecimento devam valorizar os conhecimentos advindos das pesquisas do campo educacional, para compreensão e melhor adequação em suas práticas do processo de ensino/aprendizagem.

Com relação às diretrizes curriculares nacionais, no que se refere aos cursos de formação inicial de professores, vemos que se ampliou a carga horária dos cursos, bem como se buscou a perspectiva de superar a dicotomia entre teoria e prática. É proposto que a prática deve permear a formação do aluno desde o início dos cursos, aproximando os conhecimentos específicos ao contexto real que irão encontrar em suas futuras atuações. Contudo, no estudo realizado por Scremin (2014) sobre a organização curricular de diversos cursos de licenciatura de uma IES federal, foi evidenciado que apesar da prática estar presente no início dos cursos, ainda persiste a dicotomia entre os dois polos, uma vez que há disciplinas apenas práticas e outras apenas referentes a parte teórica.

Ressaltamos ainda que diversos estudos apontam a existência da centralização do ensino universitário nos conhecimentos específicos da área. Este fato pode ser evidenciado nas próprias diretrizes específicas dos cursos da área das Ciências Exatas e da Terra, contexto deste estudo. No que tange ao perfil desejado, competências e habilidades dos formandos, é presente a valorização dos conhecimentos específicos da área sobrepostos aos conhecimentos pedagógicos. Ferreira et al (2014), ao discutirem a formação de professores, destacam que as maiores dificuldades apresentadas pelos docentes estão relacionadas ao ensino da área das Ciências Exatas e da Terra, por se tratarem de cursos objetivos e com alto grau de concentração na linguagem e conteúdos específicos da área. Nesta mesma perspectiva Almeida, Bastos e Mayer (2001, p. 02) afirmam que

a imagem de ciência mantida pela sociedade está centrada nesta visão cartesiana e é fortemente impregnada pelo positivismo, embora não tenhamos consciência deste fato. Esta imagem também mantida pelos professores influencia suas ações em sala de aula, levando-os a uma série de atitudes, como, por exemplo, a privilegiar o conhecimento científico, em detrimento do conhecimento culturalmente desenvolvido, devido ao status conferido ao primeiro por envolver a razão na sua construção; a estimular uma atitude passiva de aceitação sem questionamento das teorias científicas, consideradas como verdadeiras, enfatizando sua memorização, para evitar possíveis deturpações causadas pelas interpretações dos alunos; a desvalorizar a aplicação das ideias científicas em situações reais, de acordo com a visão de que a teoria é superior à prática, estando o poder nas mãos de quem domina a teoria.

As autoras elencam a transmissão de conteúdos, o ensino cartesiano e o ensino centralizado no conhecimento específico e em uma linguagem especialista da área de conhecimento como características da área das Ciências Exatas e da Terra, as quais não condizem com o perfil de profissional que se necessita na sociedade atual. Concordamos com Ferreira, Lúcia; Ferreira, Lucimar e Ferreira, Adriana (2014), quando defendem a importância de uma formação mais ampla e que valorize os conhecimentos pedagógicos:

Considerando aqui a área de Ciências Naturais e Exatas, um licenciado em matemática, por exemplo. Sabemos que em nossos dias o necessário não é só saber matemática para ser um bom professor, mas o fundamental é, além de saber matemática, saber como explica-la para que haja maior 
compreensão, apreensão dos conteúdos matemáticos por parte dos alunos. É importante saber trabalhar com as novas metodologias, ter conhecimento e entender o momento para introduzi-las em sua prática e qual delas poderia estar relacionando com a sua aplicação em sala de aula. (p. 230)

Nesta mesma direção, as diretrizes curriculares nacionais para a formação de professores, parecer CNE/CP n. 9/2001, apresentam como características inerentes a formação docente posturas e conhecimentos referentes a dimensão pedagógica:

Orientar e mediar o ensino para a aprendizagem dos alunos; comprometerse com o sucesso da aprendizagem dos alunos; assumir e saber lidar com a diversidade existente entre os alunos; incentivar atividades de enriquecimento cultural; desenvolver práticas investigativas; elaborar e executar projetos para desenvolver conteúdos curriculares; utilizar novas metodologias, estratégias e materiais de apoio; desenvolver hábitos de colaboração e trabalho em equipe. (Brasil, 2001, p. 4)

Outro aspecto valorizado, tanto nas DCN's, quanto nos PCN's, é a importância da aprendizagem, compreensão e execução de procedimentos investigativos e de interpretação da realidade, ou seja, a compreensão, por parte do professor em formação, da produção do conhecimento, bem como suas influências históricas e a possibilidade de diferentes modos de ensinar determinados conteúdos conectados à realidade específica do campo de futura atuação.

Nesse sentido, Libâneo e Pimenta (1999) abordam a importância da relação que deve existir entre a realidade existente e profissional em formação:

As investigações recentes sobre formação de professores apontam como questão essencial o fato de que os professores desempenham uma atividade teórico-prática. É difícil pensar na possibilidade de educar fora de uma situação concreta e de uma realidade definida. A profissão de professor precisa combinar sistematicamente elementos teóricos com situações práticas reais. (p. 267)

Durante muitos anos o modelo ideal de uma aula era aquela centrada especificamente no ensino, centrada no professor, em que a responsabilidade pela aprendizagem era apenas do aluno. Apesar de ainda encontrarmos resquícios deste modelo tradicional de ensino, é de consciência geral que esse modelo está ultrapassado e não dá conta das demandas atuais, que impetram um novo paradigma, em que o professor seja um profissional comprometido com o ensino e a aprendizagem de seus alunos. Afinal, o trabalho docente ultrapassa os limites de transmissão, mas trata-se da atividade de mediar os processos cognitivos do aluno, de forma a facilitar a compreensão de determinado conteúdo, considerando o tempo/espaço, possibilidades e limitações de seus estudantes.

A atividade docente é permeada por desafios, que dependem da mobilização individual para sua superação, uma vez que a formação inicial nos cursos de graduação e continuada nos cursos de mestrado e doutorado não preparam para o exercício superior. As diretrizes curriculares para a formação de professores trazem elementos importantes para direcionar os docentes do ensino superior dos cursos de licenciatura em suas 
práticas em sala de aula, pois a eles cabe a responsabilidade de formar futuros profissionais para a escola básica. Contudo, não há um amparo e nem iniciativas coletivas para dar suportes no sentido de colocar em prática esses elementos.

\section{A formação do formador e a excelência da formação dos futuros professores da educação básica}

Ao buscarmos discorrer sobre a excelência da formação dos estudantes que atuarão na escola básica, ressaltamos a importância de compreendermos a formação e atuação do docente do contexto universitário, partindo do pressuposto que a atuação futura dos estudantes é consequência do trabalho que vem sendo desenvolvido nas universidades.

Diversos autores reconhecem a especificidade da docência universitária, que envolve o campo da ciência de conhecimentos específicos, sem deixar de considerar a necessidade dos conhecimentos pedagógicos (Pimenta; Anastasiou, 2002). Portanto, deve haver uma articulação didática entre ambos. Contudo, ao mesmo tempo em que o professor universitário possui a responsabilidade de formar diversificados profissionais liberais e professores para atuarem na educação básica, não há uma regulamentação em forma de curso específico que dê conta de sua formação, como nos demais níveis de ensino.

A Lei de Diretrizes e Bases da Educação - lei n. 9.394/96 - é superficial ao que se refere à atividade docente, explicitando como requisito para o exercício da docência superior a preparação, não a formação, nos cursos de mestrado e doutorado, mas sem exigência da obrigatoriedade, estabelecendo como parâmetro a quantidade de no mínimo $30 \%$ dos docentes com esta titulação em cada instituição: "A preparação para o exercício do magistério superior far-se-á em nível de pós-graduação, prioritariamente em programas de mestrado e doutorado. Parágrafo único: O notório saber, reconhecido por universidade com curso de doutorado em área afim, poderá suprir a exigência de título acadêmico" (art. 66).

A própria lei sinaliza a desvalorização da profissão docente, pois os cursos stricto sensu enfatizam a pesquisa e não a docência. Sendo assim, a entrada em uma instituição de ensino superior e a progressão da carreira estão relacionados à titulação e a produção científica. Desta forma, os docentes na universidade focam seu trabalho mais para a pesquisa do que para o ensino, centrando-se em sua área de conhecimento específico, como se este domínio bastasse para o exercício da docência.

Todo professor é gestor de sua prática pedagógica, portanto, responsável pela mobilização de saberes necessários para intervir nos processos de ensino e aprendizagem. Sendo assim, destacamos a importância do reconhecimento da docência como profissão. A questão não é desconsiderarmos a formação ofertada nos cursos de pós-graduação stricto sensu, pois reconhecemos a importância do professor como pesquisador de sua própria prática. No entanto, preocupa-nos a dicotomia entre o ensino e a pesquisa, em que o trabalho docente é fundamentalmente identificado com a atividade de pesquisa, considerando esta a sua principal fonte de prestígio acadêmico e valorização profissional (Bazzo, 2008). É preciso que haja esforços institucionais para uma valorização da formação docente, para além da pesquisa, mas que enfoque o profissional 
que orienta, acolhe, que ensina, educa, conversa, compartilha, que reconhece as possibilidades de cada contexto, que avalia sua própria aprendizagem, sendo um gestor pedagógico do seu fazer.

Em relação à formação e a atuação dos professores de diversos níveis de ensino da área de Ciências, Chassot (2003) e Delizoicov, Angotti e Pernambuco (2007) fazem uma crítica com respeito a ausência de uma formação crítica e que dê conta da compreensão por parte do aluno dos fenômenos científicos que permeiam o mundo natural. Chassot (2003) defende o que ele denomina de alfabetização científica, que deveria ocorrer em todos os níveis educacionais, que trata da aquisição de uma linguagem científica por todos e que auxiliaria na compreensão e na busca de melhorias sobre os fenômenos que nos rodeiam. Já Delizoicov, Angotti e Pernambuco (2007) além de defenderem uma formação crítica, também discutem sobre os métodos de ensinar ciências, sinalizando uma necessária mudança:

Lamentavelmente, nem sequer na maioria dos Cursos de formação inicial em licenciatura essas perspectivas, tanto dos novos materiais didáticos como dos resultados de pesquisa, são consideradas. A formação de professores, na maioria dos cursos, ainda está mais próxima dos anos 1970 do que de hoje. (Delizoicov; Angotti; Pernambuco, 2007, p. 41)

Esteves (2008) também defende a formação crítica dos estudantes, trazendo como papel dos professores universitários o de

facilitar e sustentar a emergência de capacidades dos estudantes para pensarem criticamente, para serem capazes de se auto-determinarem e continuarem a aprender ao longo da vida têm vindo a ser apontadas como as tarefas centrais da ação docente. A dificuldade (e a controvérsia) estará em como proceder para concretizar tais intenções. (p. 106)

Desse modo, entendemos que ao mesmo tempo em que a prática dos docentes universitários possui resquícios de modelos de professores que tiveram durante a vida escolar e acadêmica, é necessário refletir sobre as novas demandas e sua responsabilidade como formador de profissionais que deverão contribuir para qualificar o sistema de ensino basico. Assim como cabe aos docentes universitários assumir uma postura dinâmica, com a perspectiva de formação crítica, questionando os métodos e tendo como norte de sua prática um objetivo claro e correspondente ao seu tempo e contexto histórico e social.

Nessa perspectiva, Esteves (2008) nos apresenta conceitos que traduzem o que ela denomina de excelência pedagógica:

(i) questionar os fins desse próprio ensino, antes de questionar os meios; (ii) questionar as políticas globais, regionais, nacionais de ensino superior e ciência, antes de questionar o modo como as comunidades de aprendizagem se organizam em cada instituição, em cada curso e em cada unidade curricular; (iii) questionar a sociedade e o que ela espera (e não espera) do ensino superior, antes de avaliar se tal encomenda está a ser satisfeita ou não. (Esteves, 2008, p. 102) 
Percebemos que a excelência pedagógica vai ao encontro do conceito da palavra gestão, que representa o conceito de participação, coletividade, colaboração e transparência. Ou seja, a gestão da aula do professor universitário se dá em um contexto histórico e social, em determinado espaço e tempo, que deve ter consonância com um projeto institucional, bem como os documentos que traduzem as demandas da sociedade. Desse modo, a gestão da aula não é um ato isolado, mas é norteado por objetivos pensados no e para o coletivo.

Desse modo, para se alcançar a excelência pedagógica na gestão da aula e, consequentemente na formação dos futuros educadores,

não se pode conceber na atualidade que o profissional da educação exerça a função docente sem a devida formação profissional. Esta inclui, além do domínio dos conteúdos básicos, específicos oferecidos pelos cursos de graduação a formação pedagógica para que o professor considere o aspecto técnico, instrumental na organização do ensino, e mais ainda, a dimensão política do ato pedagógico. Isso implica que o professor saiba o porque e o para que fazer de sua ação docente. (Pereira; Pereira; Carrão, 2008, p. 2)

Com vistas à necessidade da melhoria e do engajamento institucional com a formação de seus formadores, consideramos importante ressaltarmos que o requisito indispensável a uma prática comprometida do professor formador e formando é a consciência de que a gestão pedagógica é uma prática situada, historicizada contextualizada e, portanto, deve ter consonância com a realidade do contexto do país.

\section{Considerações finais}

A luz dos estudos realizados sobre o tema gestão pedagógica focada na formação dos formadores e a repercussão na formação inicial dos estudantes, cabe retomar elementos marcantes encontrados neste estudo, bem como pensar a temática em busca da qualidade do ensino na área de Ciências Exatas e da Terra.

Inicialmente ressaltamos que durante a realização deste trabalho evidenciamos a quase ausência de estudos sobre a gestão pedagógica privilegiando o contexto do ensino superior. Também percebemos que os estudos realizados sobre o tema geralmente estão relacionados à direção ou coordenação de escolas e cursos de graduação. Esse fato reforça os resultados apresentados em estudos (Pimenta; Anastasiou, 2002; Masetto, 2003; Isaia; Bolzan, 2006, 2009; Maciel, 2009; Bolzan; Isaia, 2010), em que sinalizavam a desvalorização do trabalho docente em sala de aula. Desvalorização também pelo fato da ausência de uma formação para o ensino superior, em que o ingresso na carreira docente, bem como as cobranças institucionais, estão relacionados à incessante produção científica, ficando o ensino como pano de fundo.

Sendo assim, esta não formação repercute em sentimento de insegurança, fazendo com que o docente realize a gestão de sua aula respaldada em modelos de professores que tiveram durante a educação básica ou no ensino superior. Note-se que estes modelos de aulas e de professores faziam parte de períodos e contextos bem diferente do que nos encontramos atualmente, provavelmente marcados por um período em que o professor era o centro do processo e a ele cabia a transmissão dos conteúdos. 
Do mesmo modo, os docentes universitários, como sinalizaram os estudos revisitados e os próprios documentos oficiais, servem como modelos a serem seguidos pelos seus alunos de licenciatura, que atuarão em uma posição similar. Considerando este elemento evidenciamos a responsabilidade a cargo do professor universitário em articular os conhecimentos específicos, os conhecimentos pedagógicos aos conhecimentos profissionais da área para qual está formando.

Em relação aos estudos encontrados sobre a formação dos formadores e dos estudantes dos cursos de licenciatura, focando o processo de ensino e aprendizagem da área de ciências naturais e exatas, percebemos que os estudos mais consistentes foram desenvolvidos pelos autores Ferreira, Lúcia; Ferreira, Lucimar e Ferreira, Adriana (2014), Almeida, Bastos e Mayer (2001), Delizoicov, Angotti e Pernambuco (2007) e Chassot (2003). Estes autores apontam as especificidades da área das Ciências Naturais e Exatas, sendo marcada pela centralidade na transmissão dos conteúdos específicos, sem a preocupação com a experimentação e compreensão como ciência em movimento, mas apenas com a aquisição desta como verdade absoluta, a chamada ciência morta.

Destacamos, em especial, o que Ferreira, Lúcia; Ferreira, Lucimar e Ferreira, Adriana (2014) apresentam como dado de suas pesquisas: as maiores dificuldades apresentadas pelos docentes estão relacionadas ao ensino da área das Ciências Exatas e da Terra, por se tratarem de cursos objetivos e com alto grau de concentração na linguagem e conteúdos específicos da área, organização estrutural dos currículos da área, de modo que privilegiam o estudo de conceitos, linguagem e metodologias, tornando as aprendizagens pouco eficientes para interpretação e intervenção na realidade.

O estudo realizado nos documentos oficiais, em especial as DNC's para a formação de professores e os PCN's para o ensino de Ciências, também demonstram a necessidade da alfabetização científica, ou seja, uma formação que contribua e permita que os estudantes deixem de serem os sujeitos, mas sim partícipes da linguagem científica.

Este trabalho possibilitou pensarmos sobre a formação de professores nos diversos níveis de ensino e suas práticas como um complexo de relações, envolvendo outros sujeitos, estudantes, suas trajetórias pessoais, valores, saberes e relação de poderes. Ressaltamos que não podemos responsabilizar apenas os professores pelo cenário formativo, pois sem um incentivo ou mesmo sem respaldo consistente não é possível realizar grandes transformações. É imprescindível que o poder público a e as Instituições de Educação Superior assumam a sua parte e reconheçam a complexidade da docência, sendo referentes de uma necessária ruptura cultural e cidadã.

\section{Referências}

ALMEIDA, Maria Angela; BASTOS, Heloisa; MEYER, Margareth. Entre o sonho e a realidade: comparando concepções de professores de $1^{\underline{a}}$ a $4^{\underline{a}}$ séries sobre ensino de ciências com a proposta dos PCNS. ENCONTRO NACIONAL DE PESQUISA EM EDUCAÇÃO EM CIÊNCIAS, 3, 2001. Anais... Atibaia: Nutes, 2001. Disponível em $<$ http://www.nutes.ufrj.br/abrapec/iiienpec/Atas\%20em\%20html/o62.htm>. Acesso em 3 jun. 2014. 
BOLZAN, Doris Pires Vargas; ISAIA, Silvia Maria de Aguiar. Pedagogia universitária e aprendizagem docente: relações e novos sentidos da professoralidade. Revista Diálogo Educacional, Curitiba, v. 10, n. 29, 2010, p. 13-26.

BRASIL. Lei n. 9394/96. LDB - Lei de Diretrizes e Bases da Educação Nacional. 1996. Disponível em <www.mec.gov.br>. Acesso em 15 nov. 2013.

BRASIL. Conselho Nacional de Educação. Parecer CNE/CES n. 1.301, aprovado em 06 de novembro de 2001. Diretrizes curriculares para a formação de professores em Ciências Biológicas. Disponível em <http://portal.mec.gov.br/cne/arquivos/ pdf/CES1301.pdf>. Acesso em 26 abr. 2014.

BRASIL. Parâmetros curriculares nacionais terceiro e quarto ciclos do ensino fundamental: introdução aos parâmetros curriculares nacionais. Brasília: MEC/SEF, 1998.

BRASIL. Parâmetros curriculares nacionais: Ciências naturais. Brasília: MEC/SEF, 1998.

BRASIL. Parecer CNE/CES n. 492, aprovado em 3 de abril de 2001. Diretrizes curriculares para a formação de professores dos cursos de Filosofia, História, Geografia, Serviço Social, Comunicação Social, Ciências Sociais, Letras, Biblioteconomia, Arquivologia e Museologia. Disponível em <http://portal.mec.gov.br/cne/arquivos/ pdf/CES0492.pdf>. Acesso em 26 abr. 2014.

BRASIL. Parecer CNE/CES n. 1.304, aprovado em 6 de novembro de 2001. Diretrizes curriculares para a formação de professores do curso de Física. Disponível em <http://portal.mec.gov.br/cne/arquivos/pdf/CES1304.pdf>. Acesso em 26 abr. 2014.

BRASIL. Parecer CNE/CES n. 1.302, aprovado em 6 de novembro de 2001. Diretrizes curriculares para a formação de professores do curso de Matemática. Disponível em <http://portal.mec.gov.br/cne/arquivos/pdf/CES13022.pdf>. Acesso em 26 abr. 2014.

BRASIL. Parecer CNE/CES n. 1.303, aprovado em 6 de novembro de 2001. Diretrizes Curriculares para a Formação de Professores do Curso de Química. Disponível em <http://portal.mec.gov.br/cne/arquivos/pdf/CES1303.pdf>. Acesso em 26 abr. 2014.

BRASIL. Resolução CNE/CP n. 1, de 18 de fevereiro de 2002. Institui Diretrizes Curriculares Nacionais para a Formação de Professores da Educação Básica, em nível superior, curso de licenciatura, de graduação plena. Brasília: Diário Oficial da União, 18 fev. 2014.

BRASIL. Resolução CNE/CP n. 2/2002, de 19 de fevereiro de 2002. Institui a duração e a carga horária dos cursos de licenciatura, de graduação plena, de formação de professores da Educação Básica em nível superior. Brasília: Diário Oficial da União, 15 nov. 2013.

BRASIL. Parecer CNE/CP n. 9, de 8 de maio de 2001. Diretrizes Curriculares Nacionais para a Formação de Professores da Educação Básica, em nível superior, curso de licenciatura, de graduação plena. Brasília: Diário Oficial da União, 18 jan. 2002, Seção 1, p.31. 2001b. Disponível em: <http://portal.mec.gov.br/cne/ arquivos/pdf/009.pdf>. Acesso em 18 fev. 2014.

BRASIL. Parecer CNE/CP 28, de 02 de Outubro de 2001. Dá nova redação ao Parecer CNE/CP 21/2001, que estabelece a duração e a carga horária dos cursos de Formação de Professores da Educação Básica, em nível superior. Brasília: Diário Oficial da União, 18 jan. 2002, Seção 1, p. 31. 2001a. Disponível em <http://portal.mec.gov.br/cne/arquivos/pdf/028.pdf>. Acesso em 18 fev. 2014.

CHASSOT, Ático. Alfabetização científica: uma possibilidade para a inclusão social. Revista Brasileira de Educação, São Paulo, n. 22, 2003, p. 89-100. 
COSTA, Flávia Fernandes. Formação inicial de professores: novas políticas para velhas práticas. SEMINÁRIO DE PESQUISA DA REGIÂO SUL, 9, 2012. Anais... Caxias do Sul, UCS, 2012.

COSTA, Flávia Fernandes. Inovações pedagógicas: o desafio da reconfiguração de saberes na docência universitária. In: ISAIA, Silvia Maria de Aguiar. Pedagogia universitária. Porto Alegre: PUCRS, 2009, p. 211-235.

DELIZOICOV, Demétrio; ANGOTTI, José André; PERNAMBUCO, Marta Maria. Ensino de ciências: fundamentos e métodos. São Paulo: Cortez, 2007.

ESTEVES, Manuela. Para a excelência pedagógica do ensino superior. Revista de Ciências da Educação, São Paulo, n. 7, 2008, p. 101-110.

FERREIRA, Liliana Soares. Gestão do pedagógico: de qual pedagógico se fala? Currículo sem Fronteiras. Pelotas, v. 8, n. 2, 2008, p.176-189.

FERREIRA, Liliana Soares. Professoras e professores como autores de sua professoralidade: a gestão do pedagógico na sala de aula. RBPAE, Porto Alegre, v. 25, n. 3, 2009, p. 425-438.

FERREIRA, Lúcia Garcia; FERREIRA, Lucimar Garcia; FERREIRA, Adriana Guerra. Fazer docente: reflexões em torno da formação, do trabalho e das especificidades da área de atuação docente. In: LOPES, Amélia; CAVALCANTE, Maria Auxiliadora da Silva; OLIVEIRA, Dalila Andrade; HYPÓLITO, Alvaro Moreira (orgs.). Trabalho docente e formação: políticas, práticas e investigação: pontes para a mudança. Porto: FPCUPE, 2014, p. 224-232. Disponível em <http://www.fpce.up.pt/trabalhodocenteformacao/>. Acesso em 3 mar. 2013.

HOUAIS. Dicionário houaiss da língua portuguesa. 2011. Disponível em <http://biblioteca.uol.com.br/>. Acesso em 9 out. 2013.

ISAIA, Silvia Maria de Aguiar; BOLZAN, Doris Pires Vargas. Aprendizagem docente na educação superior: construções e tessituras da professoralidade. Educação, Porto Alegre, 2006, p. 242-254.

ISAIA, Silvia Maria de Aguiar; BOLZAN, Doris Pires Vargas. Construção da profissão docente/professoralidade em debate: desafios para educação superior. ENCONTRO NACIONAL DE DIDÁTICA E PRÁTICA DE ENSINO, 13, 2006. Anais... Recife: UFPE, 2006b.

ISAIA, Silvia Maria de Aguiar; BOLZAN, Doris Pires Vargas (orgs.). Pedagogia universitária e desenvolvimento profissional docente. Porto Alegre: PUCRS, 2009.

ISAIA, Silvia Maria de Aguiar. Os movimentos da docência superior: construções possíveis nas diferentes áreas de conhecimento. Projeto de Pesquisa Institucional. CNPQ/PPGE/CE/UFSM, 2010-2013.

KRAHE, Elizabeth D. Reforma curricular de licenciaturas: Ufrgs (Brasil), UMCE (Chile) década de 1990. Porto Alegre: Ufrgs, 2008.

LIBÂNEO, José Carlos. $O$ ensino de graduação na universidade: a aula universitária. (2000). Disponível em <www.ucg.br/site_docente/edu/libaneo/pdf/ensino/pdf.> Acesso em 12 set. 2013.

LÜCK, Heloisa. Dimensões da gestão escolar e suas competências. São Paulo: Lemann, 2009. 
LUNARDI, Eliziane. Qualidade da gestão pedagógica no curso de pedagogia. Porto Alegre: PUCRS, 2012. 262f. Tese (doutorado em Educação). Pontifícia Universidade Católica do Rio Grande do Sul.

MACIEL, Adriana Moreira da Rocha. O processo formativo do professor no ensino superior: em busca de uma ambiência (trans)formativa. In: ISAIA, Sílvia Maria de Aguiar; BOLZAN, Dóris Pires Vargas; MACIEL, Adriana Moreira da Rocha (orgs.). Pedagogia universitária: tecendo redes sobre a educação superior Santa Maria: UFSM, 2009, p. 6377.

MARCELO GARCÍA, Carlos. Formação de professores: para uma mudança educativa. Porto: Porto, 1999.

MASETTO, Marcos Tarcisio. Competência pedagógica do professor universitário. São Paulo: Summus, 2003.

MENDES, Mariza. Introdução do laptop educacional em sala de aula: indícios de mudanças na organização e gestão da aula. São Paulo: PUCSP, 2008. 170f. Dissertação (mestrado em Educação). Pontifícia Universidade Católica de São Paulo.

MOROSINI, Marilia Costa. Verbetes. Enciclopédia de pedagogia universitária - glossário. v. 2. Brasília: Inep, 2006, p. 361.

OLIVEIRA, Maria Marly. Sequencia didática interativa no processo de formação de professores. Petrópolis: Vozes, 2013.

PEREIRA, Regina Coeli Barbosa; PEREIRA, Rosilene de Oliveira; CARRÃO, Eduardo Vítor Miranda. Formação de professores x excelência pedagógica. São Paulo: Centro de Pesquisas Estratégicas, 2008. Disponível em <www.ecsbdefesa.com.br/defesa/fts/FPEP.pdf>. Acesso em 12 set. 2013.

PERRENOUD, Philipe. Práticas pedagógicas, profissão docente e formação: perspectivas sociológicas. Lisboa: Dom Quixote, 1993.

PIMENTA, Selma Garrido; ANASTASIOU, Léa. Docência no ensino superior. São Paulo: Cortez, 2010.

ROMANOWSKI, Joana Paulin; ENS, Romilda Teodora. As pesquisas denominadas do tipo estado da arte em educação. Diálogo Educacional, Curitiba, v. 6, n. 19, 2006, p. 3750.

SANTOS, Miguel Augusto Meneses da Silva. Gestão de sala de aula: crenças e práticas em professores $1^{0}$ ciclo do ensino básico. Braga: Universidade do Minho, 2007. $307 f$. Tese (doutorado em Psicologia da Educação). Universidade do Minho.

SCREMIN, G. Tecido complexo formativo docente: repercussões dos conhecimentos específicos das áreas nos processos formativos das licenciaturas. Santa Maria: UFSM, 2014. 342f. Tese (doutorado em Educação). Universidade Federal de Santa Maria.

Marciele Taschetto da Silva é pedagoga, especialista em Gestão Educacional, mestre em Educação e professora da rede municipal de Canoas.

Endereço: Rua Mathias Velho, 142/301 - 91310-300 - Canoas - RS - Brasil.

E-mail: marci.tasch@gmail.com. 
Adriana Moreira da Rocha é pedagoga, psicopedagoga, mestre e doutora em Educação, professora do Departamento de Fundamentos em Educação da Universidade Federal de Santa Maria. Coordenadora do Grupo de Pesquisa Kosmos.

Endereço: Avenida Roraima, 1000, sala 3175 - 97105-900 - Santa Maria - RS Brasil.

E-mail: adrianaufsm@gmail.com.

Recebido em 4 de fevereiro de 2016.

Aceito em 23 de maio de 2016. 